\title{
Bizionia echini sp. nov., isolated from a sea urchin
}

Correspondence

Olga I. Nedashkovskaya

olganedashkovska@yahoo.com
Olga I. Nedashkovskaya, ${ }^{1}$ Marc Vancanneyt ${ }^{2}$ and Seung Bum Kim ${ }^{3}$

${ }^{1}$ Pacific Institute of Bioorganic Chemistry of the Far-Eastern Branch of the Russian Academy of
Sciences, Pr. 100 Let Vladivostoku 159, 690022 Vladivostok, Russia
${ }^{2}$ BCCM/LMG Bacteria Collection, and Laboratory of Microbiology, Ghent University,
Ledeganckstraat 35, B-9000 Ghent, Belgium
${ }^{3}$ Department of Microbiology, School of Bioscience and Biotechnology, Chungnam National
University, 220 Gung-dong, Yuseong, Daejeon 305-764, Republic of Korea

A bacterial strain, designated KMM $6177^{\top}$, was isolated from the sea urchin Strongylocentrotus intermedius and subjected to a polyphasic taxonomic investigation. The bacterium was found to be heterotrophic, aerobic, non-motile by gliding and orange-pigmented. Comparative phylogenetic analysis based on 16S rRNA gene sequencing placed the marine isolate in the genus Bizionia, a member of the family Flavobacteriaceae, with 16S rRNA gene sequence similarity of $94.9-98.6 \%$ with recognized Bizionia species. Strain KMM $6177^{\top}$ grew at $4-39{ }^{\circ} \mathrm{C}$ and with $1-8 \% \mathrm{NaCl}$. It produced alkaline phosphatase, catalase and oxidase and hydrolysed aesculin, gelatin, DNA and Tween 20 . The predominant fatty acids were iso- $\mathrm{C}_{15: 1}$, iso- $\mathrm{C}_{15: 0}$, iso$\mathrm{C}_{15: 0} 3-\mathrm{OH}$, iso- $\mathrm{C}_{17: 0} 3-\mathrm{OH}$ and a summed feature (comprising iso- $\mathrm{C}_{15: 0} 2-\mathrm{OH}$ and/or $\left.\mathrm{C}_{16: 1} \omega 7 \mathrm{c}\right)$. The DNA $\mathrm{G}+\mathrm{C}$ content was $34.4 \mathrm{~mol} \%$. A combination of phylogenetic, genotypic and phenotypic data clearly indicated that strain $\mathrm{KMM} 6177^{\top}$ represents a novel species in the genus Bizionia, for which the name Bizionia echini sp. nov. is proposed. The type strain is KMM $6177^{\top}\left(=\right.$ KCTC $22015^{\top}=$ LMG $\left.25220^{\top}\right)$.
The genus Bizionia, a member of the family Flavobacteriaceae (Bernardet et al., 2002), was created for the accommodation of heterotrophic, strictly aerobic, rodshaped, non-motile by gliding, pigmented and Gramnegative bacteria (Nedashkovskaya et al., 2005). Currently, the genus Bizionia comprises the representatives of six recognized species that were isolated from cold or moderately cold marine and saline lake environments (Bowman \& Nichols, 2005; Nedashkovskaya et al., 2005; Bercovich et al., 2008).

Here we report on the isolation and characterization of an unknown bacterial strain, designated $\mathrm{KMM} 6177^{\mathrm{T}}$, by using a polyphasic taxonomic approach. According to a comparative phylogenetic analysis based on 16S rRNA gene sequencing, strain $\mathrm{KMM} 6177^{\mathrm{T}}$ was placed in the genus Bizionia of the family Flavobacteriaceae, in which it represents a novel species.

Strain $\mathrm{KMM} 6177^{\mathrm{T}}$ was isolated from a sea urchin specimen collected from Troitsa Bay of the Sea of Japan (also known as the East Sea). For strain isolation, $0.1 \mathrm{ml}$ sea urchin tissue homogenate was plated on marine agar 2216 (Difco). After primary isolation and purification, strains were cultivated at $28{ }^{\circ} \mathrm{C}$ on the same medium and

The GenBank/EMBL/DDBJ accession number for the 16S rRNA gene sequence of Bizionia echini KMM $6177^{\top}$ is FJ716799. stored at $-80{ }^{\circ} \mathrm{C}$ in marine broth (Difco) supplemented with $20 \%(\mathrm{v} / \mathrm{v})$ glycerol.

The phylogenetic position of strain KMM $6177^{\mathrm{T}}$ was determined from its almost-complete 16S rRNA gene sequence (1448 bp). Genomic DNA extraction, PCR and sequencing of the $16 \mathrm{~S}$ rRNA gene were performed by using previously described procedures (Cho et al., 2006). The sequence obtained was aligned with those of representative members of selected genera belonging to the family Flavobacteriaceae by using PHYDIT version 3.1 (http:// plaza.snu.ac.kr/ jchun/phydit/). Phylogenetic trees were inferred by using suitable programs of the PHYLIP package (Felsenstein, 1993). Phylogenetic distances were calculated from the Jukes-Cantor model (Jukes \& Cantor, 1969), and the trees were constructed on the basis of the neighbourjoining (Saitou \& Nei, 1987), maximum-likelihood (Felsenstein, 1993) and maximum-parsimony (Kluge \& Farris, 1969) algorithms. Bootstrap analysis was performed with 1000 resampled datasets, using the SEQBOOT and CONSENSE programs of the PHYLIP package.

Comparative phylogenetic analysis of the almost complete $16 \mathrm{~S}$ rRNA gene sequence of strain KMM $6177^{\mathrm{T}}$ revealed that the strain formed a distinct lineage within the genus Bizionia, a member of the family Flavobacteriaceae (Fig. 1). The closest relative of the sea urchin isolate was Bizionia algoritergicola $\mathrm{APA}-1^{\mathrm{T}}$ (98.6\% sequence similarity). The 
sequence similarities of strain KMM $6177^{\mathrm{T}}$ with the other Bizionia species were in the range of $94.9-97.6 \%$.

For determination of the DNA base composition, DNA was isolated following the method of Marmur (1961) and the DNA G $+\mathrm{C}$ content was determined by the thermal denaturation method (Marmur \& Doty, 1962). The DNA $\mathrm{G}+\mathrm{C}$ content of strain $\mathrm{KMM} 6177^{\mathrm{T}}$ was $34.4 \mathrm{~mol} \%$.

Analysis of fatty acid methyl esters was carried out on cells grown on marine agar at $28{ }^{\circ} \mathrm{C}$ for $48 \mathrm{~h}$ in accordance with the standard protocol of the Microbial Identification System (Microbial ID). The fatty acids accounting for more than $1 \%$ of the total were iso- $\mathrm{C}_{15: 1} \mathrm{G}(21.8 \%)$, iso- $\mathrm{C}_{15: 0}$ $(17.8 \%)$, iso- $\mathrm{C}_{17: 0} 3-\mathrm{OH}(13.2 \%)$, a summed feature comprising $\mathrm{C}_{16: 1} \omega 7 c$ and/or iso- $\mathrm{C}_{15: 0}$ 2-OH $(12.3 \%)$, iso$\mathrm{C}_{15: 0} 3-\mathrm{OH}(5.4 \%)$, iso- $\mathrm{C}_{17: 1} \omega 9 c(4.0 \%), \mathrm{C}_{15: 0}(3.8 \%)$, iso- $\mathrm{C}_{16: 0} 3-\mathrm{OH}(3.4 \%)$, a summed feature comprising iso$\mathrm{C}_{17: 1} \mathrm{I}$ and/or anteiso- $\mathrm{C}_{17: 1} \mathrm{~B}(1.5 \%)$, iso- $\mathrm{C}_{16: 1}(1.2 \%)$, $\mathrm{C}_{17: 1} \omega 6 c(1.2 \%)$, iso- $\mathrm{C}_{16: 0}(1.1 \%)$ and $\mathrm{C}_{16: 0}(1.0 \%)$.

Physiological and biochemical properties of strain KMM $6177^{\mathrm{T}}$ were determined by using previously described methods (Nedashkovskaya et al., 2004). API 20 E, API 20 NE, API 32 GN and API ZYM galleries (bioMérieux) were also used for studying the phenotypic features of the strain according to the manufacturer's instructions, except that the galleries were incubated at $28{ }^{\circ} \mathrm{C}$. Susceptibility to antibiotics was tested using additional discs containing cefalexin $(30 \mu \mathrm{g})$, cefazolin $(30 \mu \mathrm{g})$, chloramphenicol $(30 \mu \mathrm{g})$, doxycycline $(10 \mu \mathrm{g})$, erythromycin $(15 \mu \mathrm{g})$, nalidixic acid $(30 \mu \mathrm{g})$, ofloxacin $(5 \mu \mathrm{g})$, oxacillin $(10 \mu \mathrm{g})$, rifampicin $(5 \mu \mathrm{g})$ and vancomcin $(30 \mu \mathrm{g})$.

Cells of strain KMM $6177^{\mathrm{T}}$ were Gram-negative, aerobic, non-motile by gliding and formed circular, mucous and orange-pigmented colonies on marine agar after cultivation for $48 \mathrm{~h}$ at $28{ }^{\circ} \mathrm{C}$. Other phenotypic characteristics of the strain studied are given in the species description and in Table 1. Strain KMM $6177^{\mathrm{T}}$ shared many similar phenotypic features with recognized species of the genus Bizionia. It is characterized by a respiratory type of metabolism, by the absence of gliding motility, by production of catalase, oxidase and gelatinase, and by the inability to form acid from carbohydrates, to produce nitrate reductase and to hydrolyse starch (Table 1). However, the novel isolate differed from all recognized Bizionia species by the maximal growth temperature, by the presence of aesculin and citrate utilization and by the absence of casein hydrolysis (Table 1). In contrast to its closest neighbour, B. algoritergicola, strain $\mathrm{KMM} 6177^{\mathrm{T}}$ did not produce arginine dihydrolase, hydrolyse urea or utilize L-histidine. These strains can be clearly differentiated from each other by the growth temperature range $\left(4-39{ }^{\circ} \mathrm{C}\right.$ for $\mathrm{KMM} 6177^{\mathrm{T}}$ and -2 to $25{ }^{\circ} \mathrm{C}$ for B. algoritergicola APA$1^{\mathrm{T}}$ ). Furthermore, strain KMM $6177^{\mathrm{T}}$ had a lower DNA $\mathrm{G}+\mathrm{C}$ content in comparison with $B$. algoritergicola strain APA $-1^{\mathrm{T}}$ (34.4 vs $45 \mathrm{~mol} \%$ ). Consequently, the phenotypic distinctiveness between the novel isolate and B. algoritergicola strongly supports the results of 16S rRNA gene phylogenetic analysis ( $98.6 \%$ sequence similarity). In this case, determination of the degree of DNA-DNA reassociation was not needed for confirmation of delineation of strain $\mathrm{KMM} 6177^{\mathrm{T}}$ as a novel species from its nearest phylogenetic neighbour, B. algoritergicola APA- $1^{\mathrm{T}}$, because DNA-DNA hybridization experiments should be carried out for strains sharing $16 \mathrm{~S}$ rRNA gene sequence similarities higher than about $99 \%$ according to the proposal of Stackebrandt \& Ebers (2006). Differences in phenotypic and genotypic traits between strain KMM $6177^{\mathrm{T}}$ and other species of the genus Bizionia are presented in Table 1.

Therefore, on the basis of the phylogenetic distances and phenotypic and genotypic data obtained, it is suggested that strain KMM $6177^{\mathrm{T}}$ represents a novel species within the genus Bizionia, for which the name Bizionia echini sp. nov. is proposed.

\section{Description of Bizionia echini sp. nov.}

Bizionia echini (e.chi'ni. L. gen. n. echini of/from a sea urchin).

The main characteristics are as given by Nedashkovskaya $e t$ al. (2005) for the genus. In addition, cells are $0.4-0.5 \mu \mathrm{m}$ wide and 1.4-3.5 $\mu \mathrm{m}$ long. On marine agar, colonies are

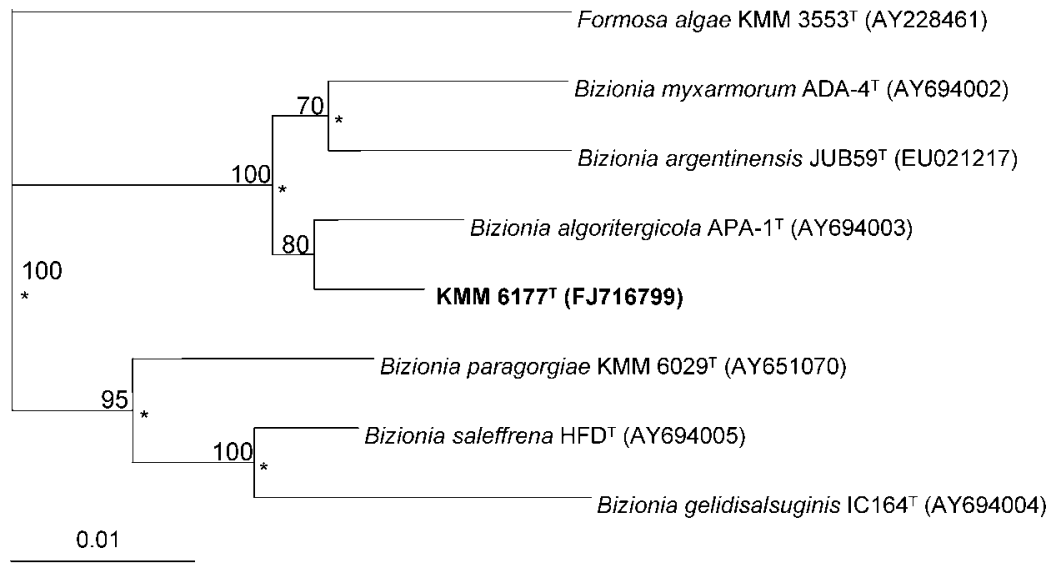

Fig. 1. Phylogenetic tree of Bizionia species based on the $16 \mathrm{~S}$ rRNA gene sequences. The tree was constructed using the Jukes-Cantor model and neighbour-joining algorithm. The asterisks indicate branches that were also recovered in the maximum-likelihood and maximum-parsimony trees. The numbers at nodes indicate the levels of bootstrap support (\%). Only $50 \%$ or higher values are indicated. Scale bar, 0.01 nucleotide substitutions per position. 
Table 1. Differential phenotypic characteristics of Bizionia species

Species: 1, KMM $6177^{\mathrm{T}}$; 2, Bizionia algoritergicola; 3, Bizionia argentinensis; 4, Bizionia gelidisalsuginis; 5, Bizionia myxarmorum; 6, Bizionia paragorgiae; 7, Bizionia saleffrena. Data from Bowman \& Nichols (2005), Nedashkovskaya et al. (2005), Bercovich et al. (2008) and this study. All strains were positive for the following characteristics: oxidase, catalase and alkaline phosphatase activities; and hydrolysis of gelatin. All strains were negative for the following characteristics: gliding motility; nitrate reductase, $\alpha$-galactosidase, $\beta$-galactosidase, $\alpha$-glucosidase, $\beta$-glucosidase, $N$-acetyl$\beta$-glucosaminidase and $\alpha$-fucosidase activities; flexirubin-type pigment production; hydrolysis of starch; acid production from carbohydrates; utilization of adipate; and indole production. O, Orange; Y, yellow; ND, not detected.

\begin{tabular}{|c|c|c|c|c|c|c|c|}
\hline Characteristic & 1 & 2 & 3 & 4 & 5 & 6 & 7 \\
\hline Colony colour & $\mathrm{O}$ & $\mathrm{Y}$ & $\mathrm{Y}-\mathrm{O}$ & $\mathrm{Y}$ & $\mathrm{Y}$ & $\mathrm{Y}$ & $\mathrm{Y}$ \\
\hline Arginine dihydrolase & - & + & + & + & + & - & - \\
\hline $\mathrm{H}_{2} \mathrm{~S}$ production & + & + & - & $\mathrm{ND}$ & - & + & $\mathrm{ND}$ \\
\hline Temperature range $\left({ }^{\circ} \mathrm{C}\right)$ & $4-39$ & -2 to 25 & $2-28$ & -2 to 29 & -2 to 30 & $4-36$ & -2 to 25 \\
\hline Salinity range $(\%)$ & $1-8$ & $1-10$ & $1-6$ & $1-17$ & $1-10$ & $1-8$ & $1-17$ \\
\hline \multicolumn{8}{|l|}{ Hydrolysis of: } \\
\hline Aesculin & + & - & - & - & - & - & - \\
\hline Casein & - & + & + & + & + & + & + \\
\hline DNA & + & + & - & - & + & - & - \\
\hline Urea & - & + & - & - & + & - & + \\
\hline Tween 20 & + & + & $\mathrm{ND}$ & $\mathrm{ND}$ & - & - & $\mathrm{ND}$ \\
\hline Tween 80 & + & + & - & - & + & + & + \\
\hline \multicolumn{8}{|l|}{ Utilization of: } \\
\hline D-Glucose, D-mannose & + & + & - & - & + & - & - \\
\hline Citrate & + & - & - & - & - & - & - \\
\hline L-Histidine & - & + & + & + & + & - & + \\
\hline \multicolumn{8}{|l|}{ Susceptibility to: } \\
\hline Carbenicillin, tetracycline & + & + & ND & ND & - & + & ND \\
\hline Benzylpenicillin & + & + & $\mathrm{ND}$ & $\mathrm{ND}$ & + & - & $\mathrm{ND}$ \\
\hline Streptomycin & - & - & $\mathrm{ND}$ & $\mathrm{ND}$ & + & + & $\mathrm{ND}$ \\
\hline Neomycin & - & - & $\mathrm{ND}$ & $\mathrm{ND}$ & + & - & ND \\
\hline DNA G $+\mathrm{C}$ content $(\mathrm{mol} \%)$ & 34.4 & 45.0 & 34.0 & 39.0 & 43.0 & $37-38$ & 40.0 \\
\hline
\end{tabular}

circular, mucoid, orange-pigmented, shiny, with entire edges and 2-4 $\mathrm{mm}$ in diameter. Growth occurs with 1-8\% $\mathrm{NaCl}$ and at $4-39{ }^{\circ} \mathrm{C}$. Optimal growth is observed with $2-3 \% \mathrm{NaCl}$. Oxidase, catalase and alkaline phosphatase activities are present. Arginine dihydrolase, lysine and ornithine decarboxylases and tryptophan deaminase activities are absent. Decomposes aesculin, gelatin, DNA and Tweens 20, 40 and 80. Does not hydrolyse agar, casein, starch, CM-cellulose, urea or chitin. Produces no acid from L-arabinose, cellobiose, D-fructose, L-fucose, D-galactose, D-glucose, D-lactose, maltose, melibiose, raffinose, Lrhamnose, sucrose, DL-xylose, $\mathrm{N}$-acetylglucosamine, adonitol, dulcitol, glycerol, inositol or mannitol. Utilizes mannose, but not lactose, sucrose, inositol or sorbitol. According to the API 20 NE gallery, glucose, arabinose, mannitol, $\mathrm{N}$-acetylglucosamine, maltose, malate, gluconate, citrate and phenylacetate are also utilized. None of the API $32 \mathrm{GN}$ tests indicate a positive reaction, and only two tests (citrate utilization and gelatin hydrolysis) from the API 20 E gallery are positive for the type strain. Testing by using the API ZYM gallery for the type strain indicates that esterase (C4), esterase lipase (C8), leucine arylamidase, valine arylamidase, cystine arylamidase, trypsin, acid phosphatase and naphthol-AS-BI-phosphohydrolase activities are present, but lipase (C14), $\alpha$-chymotrypsin, $\alpha$ - and $\beta$-galactosidases, $\alpha$ - and $\beta$-glucosidases, $\beta$-glucuronidase, $N$-acetyl- $\beta$-glucosaminidase, $\alpha$-mannosidase and $\alpha$-fucosidase activities are absent. Nitrate is not reduced. $\mathrm{H}_{2} \mathrm{~S}$ is produced but indole is not. Susceptible to ampicillin, benzylpenicillin, carbenicillin, cefalexin, chloramphenicol, erythromycin, doxycycline, lincomycin, ofloxacillin, oleandomycin, rifampicin, tetracycline and vancomycin; resistant to cefazolin, gentamicin, kanamycin, nalidixic acid, neomycin, oxacillin, polymixin and streptomycin. The predominant fatty acids of strain KMM $6177^{\mathrm{T}}$ are iso- $\mathrm{C}_{15: 1}$ $\mathrm{G}$, iso- $\mathrm{C}_{15: 0}$, iso- $\mathrm{C}_{15: 0} 3-\mathrm{OH}$, iso- $\mathrm{C}_{17: 0} 3-\mathrm{OH}$ and a summed feature comprising $\mathrm{C}_{16: 1} \omega 7 c$ and/or iso- $\mathrm{C}_{15: 0}$ 2-OH. The DNA G + C content is $34.4 \mathrm{~mol} \%$.

The type strain is $\mathrm{KMM} 6177^{\mathrm{T}}\left(=\mathrm{KCTC} 22015^{\mathrm{T}}=\mathrm{LMG}\right.$ $25220^{T}$ ), isolated from the sea urchin Strongylocentrotus intermedius collected from Troitsa Bay, Gulf of Peter the Great, the Sea of Japan (also known as the East Sea).

\section{Acknowledgements}

This research was supported by grants from the Far-Eastern Branch of the Russian Academy of Sciences no. 09-III-A-06-228 and Presidium of the Russian Academy of Sciences 'Molecular and Cell Biology', and by State Contract 02.518.11.7169 from the Federal Agency for Science and Innovations of the Russian Federation. 


\section{References}

Bercovich, A., Vazaquez, S. C., Yankilevich, P., Coria, S. H., Foti, M., Hernández, E., Vidal, A., Ruberto, L., Melo, C. \& other authors (2008). Bizionia argentinensis sp. nov., isolated from surface marine water in Antarctica. Int J Syst Evol Microbiol 58, 23632367.

Bernardet, J.-F., Nakagawa, Y. \& Holmes, B. (2002). Proposed minimal standards for describing new taxa of the family Flavobacteriaceae and emended description of the family. Int J Syst Evol Microbiol 52, 1049-1070.

Bowman, J. P. \& Nichols, D. S. (2005). Novel members of the family Flavobacteriaceae from Antarctic maritime habitats including Subsaximicrobium wynnwilliamsii gen. nov., sp. nov., Subsaximicrobium saxinquilinus sp. nov., Subsaxibacter broadyi gen. nov., sp. nov., Lacinutrix copepodicola gen. nov., sp. nov., and novel species of the genera Bizionia, Gelidibacter and Gillisia. Int J Syst Evol Microbiol 55, 1471-1486.

Cho, S. H., Han, J. H., Seong, C. N. \& Kim, S. B. (2006). Phylogenetic diversity of acidophilic sporoactinobacteria isolated from various soils. J Microbiol 44, 600-606.

Felsenstein, J. (1993). PHYLIP (phylogeny inference package), version 3.5c. Distributed by the author. Department of Genome Sciences, University of Washington, Seattle, USA.
Jukes, T. H. \& Cantor, C. R. (1969). Evolution of protein molecules. In Mammalian Protein Metabolism, vol. 3, pp. 21-132. Edited by H. N. Munro. New York: Academic Press.

Kluge, A. G. \& Farris, J. S. (1969). Quantitative phyletics and the evolution of anurans. Syst Zool 18, 1-32.

Marmur, J. (1961). A procedure for the isolation of deoxyribonucleic acid from microorganisms. J Mol Biol 3, 208-218.

Marmur, J. \& Doty, P. (1962). Determination of the base composition of deoxyribonucleic acid from its thermal denaturation temperature. J Mol Biol 5, 109-118.

Nedashkovskaya, O. I., Kim, S. B., Han, S. K., Rhee, M. S., Lysenko, A. M., Falsen, E., Frolova, G. M., Mikhailov, V. V. \& Bae, K. S. (2004). Ulvibacter litoralis gen. nov., sp. nov., a novel member of the family Flavobacteriaceae isolated from the green alga Ulva fenestrata. Int $J$ Syst Evol Microbiol 54, 119-123.

Nedashkovskaya, O. I., Kim, S. B., Lysenko, A. M., Frolova, G. M., Mikhailov, V. V. \& Bae, K. S. (2005). Bizionia paragorgiae gen. nov., sp. nov., a novel member of the family Flavobacteriaceae isolated from the soft coral Paragorgia arborea. Int J Syst Evol Microbiol 55, 375-378.

Saitou, N. \& Nei, M. (1987). The neighbor-joining method: a new method for reconstructing phylogenetic trees. Mol Biol Evol 4, 406-425.

Stackebrandt, E. \& Ebers, J. (2006). Taxonomic parameters revisited: tarnished gold standards. Microbiol Today 33, 152-155. 